http://dx.doi.org/10.30681/23588403v14i0102

\title{
UM ESTUDO SEMÂNTICO ENUNCIATIVO DA PALAVRA IMIGRANTE NA RESOLUÇÃO NORMATIVA 002/2019 VIGENTE NO ESTADO DE MATO GROSSO
}

\author{
Elizene Pires de PAULA ${ }^{1}$ \\ Francineli Cezarina LARA ${ }^{2}$ \\ Lucilene Justina da SILVA ${ }^{3}$
}

Data de recebimento: 10/04/2021

Data de aceite: 23/05/2021

Resumo: O presente trabalho surgiu da inquietação em verificar numa perspectiva semântica enunciativa uma possível relação da palavra imigrante e sua diversa designação. Para o nosso corpus utilizamos a Resolução normativa 002/2019, que está vigente do Estado de Mato Grosso, e o embasamento teórico recorremos a Semântica de Enunciação de, Guimarães (2002/2018), e nos servirão de aporte para desenvolvermos as análises, alguns autores que já desenvolveram trabalhos pensados a partir desse lugar teórico-metodológico - Dias (2010, 2011, 2013), Zoppi-Fontana (2009, 2010, 2011), Zattar (2013) e Karim (2012, 2013). Para a Semântica do Acontecimento a análise do sentido da linguagem deve localizar-se no estudo da enunciação, o acontecimento do dizer.

Palavras-chave: Imigrantes. Semântica do Acontecimento. Reescrituração.

\begin{abstract}
The present work arose from the concern to verify in an enunciative semantic perspective a possible relationship between the word immigrant and its diverse designation. For our corpus, we used the Normative Resolution 002/2019, which is in force in the State of Mato Grosso, and the theoretical basis we use the Enunciation Semantics of Guimarães (2002/2018), which will serve as a contribution to develop the analyses, some authors who have already developed works thought from this theoreticalmethodological place - Dias (2010, 2011, 2013), Zoppi-Fontana (2009, 2010, 2011), Zattar (2013) and Karim (2012, 2013). For the Semantics of the Event, the analysis of the meaning of language must be located in the study of enunciation, the event of saying.
\end{abstract}

Keywords: Immigrants. Semantics of the Event. Rewriting.

\section{Introdução}

Este artigo propõe investigar os diversos sentidos que permeiam a palavra imigrante na Resolução normativa 002/2019, que está vigente do Estado de Mato Grosso, partindo de uma perspectiva semântica enunciativa. Sabe-se que desde há muito tempo até os dias atuais o ser

\footnotetext{
1 Graduanda Licenciatura em Letras-Habilitação em Língua e Literaturas de Língua Portuguesa e Língua Espanhola. ORCID: https://orcid.org/0000-0001-6437-1896.nselizene@gmail.com

2 Prof. ${ }^{\text {a }}$. Orientadora Doutoranda em linguística pela Universidade Complutense de Madrid em cotutela pela Universidade do Estado de Mato Grosso, Integrante do grupo de estudos Cnpq: Mato Grosso modos de dizer e falares. Membro do projeto de pesquisa: Significar Mato Grosso. Membro do grupo de pesquisa LALINGAP e MIRIADI. ORCID: Https://orcid.org/0000-0001-9621-158X. lara.francineli@gmail.com

3 Graduanda Licenciatura em Letras-Habilitação em Língua e Literaturas de Língua Portuguesa e Língua Espanhola. ORCID: Https://orcid.org/0000-0002-7779-3323. lucilenejustina86@hotmail.com.
} 


\section{Revista de Estudos Acadêmicos de Letras}

humano se muda para países diferentes dos que habitam, são inúmeros os motivos que levam para que esse fato aconteça.

Esses deslocamentos nem sempre acontecem de maneira natural: há dois processos relevantes que podem levar à consideração dos termos imigrante/estrangeiros: o primeiro ocorre por fatores voluntários; e o segundo por princípios involuntários, ou seja, por obrigações causadas por diferentes fatores, tais como: invasões colonizadoras, fugas de guerras, migrações forçadas, perseguições políticas, raciais, religiosas e outras, caracterizando uma condição forçada e por isso violenta. As que são consideradas voluntárias são movidas por sentimentos diversos - acompanhamento de familiares, melhores condições de trabalho e de vida em que o indivíduo busca novas oportunidades de emprego, conhecer culturas novas, melhorar suas habilidades linguísticas, afetividades subjetivas a condição humana - e que ao longo da história agregam novos motivos e características na prática desse recurso empreendido pelos Homens.

Enquanto direito, ambas as categorias voluntárias ou involuntárias, são amparadas por leis internacionais. Partindo desta perspectiva este trabalho buscará compreender o funcionamento enunciativo da palavra "imigrante" na Resolução normativa 002/2019 e como esse termo vem significando.

Para fundamentar nossas análises interpretativas, tomamos como viés norteador, os levantamentos teóricos da Semântica do Acontecimento, Guimarães (2002, 2005, 2011 e 2018), teoria pela qual se sustenta a ideia de que os sentidos da palavra não são fixos e nem se reduzem a um conceito ou definição, ou seja, esse sentido se constrói no enunciado. Buscamos compreender a linguagem como relação de sentidos em que se inclui a materialidade da língua, da história e do sujeito que enuncia. Inicialmente, teceremos algumas considerações sobre a palavra imigrantes.

Tomamos como corpus, para analisar a relação de sentidos da palavra imigrantes, um material que se constitui enquanto a Resolução normativa 002/2019.

\section{Historização}

Em o Novo Testamento os cristãos são chamados de "peregrinos" na primeira carta de Pedro, capitulo 2, versículo 11, (1 Pe 2,11), isto é, "apenas imigrantes", de passagem nesta terra (Há 13, 14): "Porque não temos aqui cidade permanente, mas buscamos a futura". Como para Jesus, também para o discípulo a condição de estrangeiro. 


\section{Revista de Estudos Acadêmicos de Letras}

No Brasil o processo migratório teve início em 1530, causada por diversos fatores, em que as pessoas migravam para outros países em busca de melhores condições de vida e de trabalho.

A constituição de 1988 é um documento base que abrange as atuais leis, regras, e normas da República Federativa do Brasil, foi promulgada no dia 05 de outubro de 1988 durante o governo de José Sarney. Segundo o representante da mesa constituinte Guimarães, (1988, p. 01), "A constituição certamente não é perfeita. Ela própria o confessa, ao admitir a reforma. Quanto a ela, discordar? Sim. Divergir? Sim. Descumprir? Jamais. Afrontá-la? Nunca!"

A constituição assegura direitos fundamentais do país que envolve os direitos individuais a cada cidadão no país seja social, políticos e jurídicos. Pode-se dizer que a Constituição é a estrutura jurídica do país sendo nossa base para a democracia.

Para os cidadãos imigrantes a constituição assegura em seu artigo $5^{\circ}$ que todos são iguais perante a lei sem distinção de qualquer natureza, garantido aos estrangeiros residentes no país a inviolabilidade do direito à vida, a liberdade, a igualdade e a segurança, sendo o mais longo da constituição, ele trata os direitos fundamentai e coloca uma relação de distinção entre cidadãos e direitos, e também há uma diferença, mesmo que se busque ali um aspecto de igualdade

O direito a educação está legitimado na constituição em que o acesso à educação deve ser direito de todos os cidadãos brasileiros e imigrantes, em seu artigo $6^{\circ}$, destaca que o cidadão tanto brasileiro quanto estrangeiro tenha acesso a educação, mas são dissemelhantes mesmo na busca pela igualdade, no qual espera-se dos poderes públicos que se faça cumprir as devidas prestações assertivas para sua implementação. Conforme Guimarães, (1988, p.01). “A constituição pretende ser a voz, a letra, a vontade política da sociedade rumo à mudança. Que a promulgação seja nosso grito: mudar para vencer! Muda brasil!”. A constituição não é uma Lei comum, é a Lei fundamental, a "mãe de todas as leis".

Outra lei importante que estudamos é lei de $\mathrm{n}^{\circ} 13.445$ de 24 de maio de 2007, que institui a Lei de Migração, regula a entrada e saída de migrantes, torna-se público os direitos e deveres do migrante, estabelecendo princípios e diretrizes para as políticas públicas para o emigrante, designando o imigrante como: pessoa nacional de outro país ou apátrida que trabalha ou reside e se estabelece temporária ou definitivamente no Brasil. Esta lei, reforça em sua totalidade o respeito ao ser humano independente de sua nacionalidade, e traz garantias que nortearão alguns princípios da política migratória no Brasil, em que se destacam-se nos seus artigos, a não criminalização do migrante, o acesso à educação, moradia e seguridade social, diretos e 


\section{Revista de Estudos Acadêmicos de Letras}

liberdades civis, direito à liberdade de circulação em território nacional, e o direitos a educação pública.

Observa-se que o número de imigrantes no mundo, atualmente, segundo estimativa do relatório de migração global 2020, é aproximadamente cerca de 272 milhões de imigrantes internacionais, sendo dois terços desses considerados migrantes de mão-de-obra.

Os primeiros imigrantes do Brasil, chegaram no final do século XIX. Muitos saíram de seus locais de origem em busca de condições melhores de vida e visava conseguir empregos e terras para trabalhar, outros grupos vieram fugindo de guerras ou perseguições religiosa, alemães, italianos, sírios, libaneses, espanhóis e japoneses chegam ao Brasil com mão de obra mais capacitada que os escravos, os imigrantes colonizavam grande parte do Brasil desenvolvendo novas lavouras e mesclando seus conhecimentos e suas culturas nas construções de uma nova nação.

No Brasil, os imigrantes regressaram em grande número no ano 2000, conforme o censo demográfico $\left(\right.$ IBGE) ${ }^{4}$, apontou que devido as crises político-econômica e climática em países como o Haiti, algumas nações da África, do Oriente Médio, como por exemplo a Síria, e a recente e profunda crise na Venezuela.

De acordo com o IBGE e a Polícia Federal, indicam que há presença de imigrantes nos Estados e municípios brasileiros, e foram registrados cerca e 466 mil imigrantes no país, segundo enfatizou o IBGE (2019), os mesmos possuem em geral o nível médio de escolaridade, e não dominam outro idioma além do nativo e chegam em situação de vulnerabilidade social e econômica.

O estado de Mato Grosso ${ }^{5}$ é uma das 27 unidades federativas do Brasil e está localizado na região Centro-Oeste, dividindo-se em 141 municípios, sendo os mais populosos e importantes: a capital Cuiabá, Várzea Grande, Rondonópolis, Sinop, Tangará da Serra, Barra do Garças e Cáceres.

Como o Estado de Mato Grosso é constituído na sua dimensão territorial por uma diversidade de culturas, as propostas pedagógicas elaboradas pelos municípios e os Projetos

\footnotetext{
${ }^{4}$ Este enunciado podemos encontrar em: https://g1.globo.com/politica/noticia/2019/09/25/apenas-5percent-dosmunicipios-com-presenca-de-imigrantes-e-refugiados-no-brasil-oferecem-servicos-de-apoio-aponta-ibge.ghtml

${ }^{5}$ Este enunciado podemos encontrar em:

https://teatur.com.br/destinations/matogrosso/\#: :text=Mato\%20Grosso\%20\%C3\%A9\%20uma\%20das\%2027\% 20unidades $\% 20$ federativas $\% 20$ do $\% 20$ Brasil.\&text $=$ Mato $\% 20$ Grosso $\% 20$ est $\%$ C $3 \%$ A $1 \% 20$ organizado $\% 20 \mathrm{em}, \mathrm{B}$ arra\%20do\%20Gar\%C3\%A7as\%20e\%20C\%C3\%A1ceres
} 


\section{Revista de Estudos Acadêmicos de Letras}

Políticos Pedagógicos das unidades escolares das redes pública e privada precisam propiciar as crianças conhecer e respeitar diferentes modos de vida, saberes e costumes dos diferentes grupos sociais como: povos indígenas, ribeirinhos, as comunidades quilombolas e demais afrodescendentes, população do campo, imigrantes, estrangeiros, população circense e cigana, não podendo esquecer do ensino da cultura raiz Mato-Grossense.

O Ministério de Estado do Desenvolvimento Regional, incluiu Cáceres situada a oeste de Mato Grosso, como cidade gêmea com o município de San Matias na Bolívia, o intuito da junção das cidades fronteiriças é de impulsionar o desenvolvimento econômico e viabilizar o acesso ao serviço público.

A pesquisa intitulada "Cáceres e San Matias na perspectiva de cidades-gêmeas, um estudo de possibilidades", realizada pelos docentes do departamento de História da Universidade do Estado do Mato Grosso, define que, as duas cidades se articulam, políticoeconômicas e socioculturais de ambos os lados, e que, o reconhecimento das cidades-gêmeas minimiza a burocracia em relação às populações que transitam na fronteira e potencializa a integração econômica, social e cultural entre os dois países.

O município de Cáceres-MT, segundo dados do IBGE, em 2020, tem uma população estimada em 94.861 e possui 38 escolas municipais, sendo 13 escolas do campo e 25 escolas da zona urbana, totalizando 8.928 alunos matriculados e devidamente enturmados e ativos no ano 2020. Dentre esse total de alunos a um número significativo de estrangeiros distribuídos entre as escolas do campo e a escolas a zona urbana sendo 71 (setenta e um) alunos com país de nascimento Bolívia, 6 (seis) alunos da Espanha e 1 (um) da Itália e tem alunos que não foram informados o país de seu nascimento.

Considerando esse número de alunos fomos buscar como está sendo especificado o ensino da língua estrangeira no Documento de Referência Curricular do Estado de Mato Grosso. Notamos que na área de Linguagens, anos finais, da BNCC, estão inseridos quatro componentes curriculares: Língua Portuguesa, Língua Estrangeira (Inglês e Espanhol), Arte e Educação Física. Segundo o termo linguagens abrange a linguagem verbal, a musical, a visual e a corporal (BNCC, 2017, p. 61).

Nesta perspectiva, podemos observar na Base Nacional Comum Curricular especificamente em língua estrangeira (Espanhol), que é uma atividade que exige mais tempo e dedicação por conta do preconceito acerca de sua necessidade, em um país que aprender outra língua é ter acesso a novas formas de cidadania, tanto quanto aprender a expressar-se através do seu corpo, em práticas artísticas (em todas as suas especificidades), desportivas, através das 


\section{Revista de Estudos Acadêmicos de Letras}

práticas corporais e não se limitando a uma leitura , e sim, a partir da gestualidade da linguagem corporal, vista como texto da cultura em uma conjectura da linguagem verbal e não verbal.

É importante observar que as competências dessa área estão relacionadas às competências gerais da BNCC. Estas ultrapassam os conteúdos disciplinares, tornando-se um instrumento que orientará as práticas educacionais ao encontro do futuro, proporcionando aos alunos o conhecimento necessário. Assim, é possível perceber, neste documento, a intenção de promover e melhorar os estudos em linguagens no Ensino Básico.

De acordo com documento imprensa disponibilizado pela Seduc-MT em 26 de junho de 2016, até a presente data, a rede de educação já estava atendendo seis países, além da Bolívia, Síria, Haiti e Rússia, as escolas acolheram alunos do Canada e da China, para garantir um atendimento de qualidade na rede estadual de ensino de MT para os estudantes.

Conforme foram chegando os imigrantes nos municípios brasileiros, o Estado de Mato Grosso juntamente com a Secretaria de Estado de Educação e Lazer (SEDUC) desenvolveram a Política de Educação para os imigrantes, em que proposta seria submetida ao conselho Estadual de Educação (CEE) no dia 05/07/2016.

O Conselho Estadual de Educação de Mato Grosso instituiu através da resolução normativa $n^{\circ}$ 002/2019- CEE/MT, normas para oferta da educação básica para imigrantes, onde este documento é embasado em seus artigos, em que destaca a garantia do imigrante ao acesso a serviços públicos educacionais sem discriminação em razão a sua nacionalidade, acesso igualitário a educação, e vem enfatizando que, o não domínio da língua nacional não deve ser barreira para que o estudante estrangeiro seja incluído no sistema educacional, e que as escolas estejam preparadas para ofertar um atendimento humanizado incluso e acolhedor.

O estudante deverá ser matriculado na escola que oferta a Política Pública de Educação para imigrantes, com objetivo de aprender a Língua Portuguesa, e ser incluso no processo de educação formal, e assim que o aluno obtiver as condições necessárias, deverá passar pelo processo de classificação, e, a seguir matricular-se no ensino regular da Educação Básica.

A escola que ofertar a educação para estrangeiro devera matricular o estudante imigrante na etapa e/ou modalidade pertinente e, após alcance do domínio da Língua Portuguesa o estudante deverá passar pelo processo de classificação.

Diante do exposto ao fazer uma pesquisa na internet no documento da Base Nacional Comum Curricular Comum Curricular (BNCC), que é um documento de caráter normativo que define o conjunto orgânico e progressivo de aprendizagens essenciais que todos os alunos devem desenvolver ao longo das etapas e modalidades da Educação Básica, foi constatado que 


\title{
Revista de Estudos Acadêmicos de Letras
}

o referido documento criado pelo Ministério da Educação (MEC) com objetivo de orientar as escolas a desenvolver um ensino unificado, não possui uma estrutura específica de ensino para atender os estudantes imigrantes, desta maneira não há na BNCC um planejamento que regulamenta o ensino para esses estudantes, e nem orientação para os profissionais da educação.

\section{Semântica do Acontecimento}

A partir de agora iremos descrever o processo metodológico, pelo qual desenvolveremos este estudo, destacando noções pertinentes à teoria da Semântica do Acontecimento, conforme formulados por Guimarães $(2002,2018)$, sendo que essa teoria será base para análise dos recortes.

A semântica do Acontecimento propõe-se a tratar a significação a partir do acontecimento do dizer, um acontecimento que temporaliza, pois para Guimarães (2002), "não é o sujeito que temporaliza é o acontecimento", o acontecimento instala sua própria temporalidade, não considerando, assim, o empirismo do sujeito falante. Guimarães (idem) diz que:

[...] o acontecimento de enunciação constitui sentido instalando uma temporalidade específica (passado, presente, futuro). Deste modo o sujeito na enunciação é constituído por esta temporalidade não sendo origem nem desta temporalidade, nem do acontecimento. Para estudar o modo de estudar o sentido dos nomes na enunciação [...] (GUIMARÃES, 2002, p.12)

Para o lugar teórico por nós aqui assumido, a temporalidade não se refere ao tempo cronológico, mas sim, a um acontecimento que instala uma temporalidade específica no seu presente e, segundo Guimarães:

\begin{abstract}
A temporalidade do acontecimento constitui o seu presente e um depois que abre o lugar dos sentidos, e um passado que não é lembrança ou recordação pessoal de fatos anteriores. O passado é, no acontecimento, rememoração de enunciações, ou seja, se dá como parte de uma nova temporalização, tal como a latência do futuro. Ë nessa medida que o acontecimento é diferença na sua própria ordem: o acontecimento é sempre uma nova temporalização, um novo espaço de convivialidade de tempos, sem a qual não há sentido, não há acontecimento de linguagem, não há enunciação. (GUIMARÃES, 2002, p.15).
\end{abstract}

Para o autor, a relação entre formas linguísticas constitutivas de um enunciado que integrar um texto é marcada por certos procedimentos específicos como a reescrituração e as relações de articulação. Um dos procedimentos de análises que nos valeremos neste trabalho é a reescrituração e que segundo Guimarães (2005): 


\section{Revista de Estudos Acadêmicos de Letras}

A reescrituração designa um conjunto de procedimentos de textualidade pelos quais a enunciação de um texto rediz insistentemente o que já foi dito. Assim a textualidade e o sentido das expressões se constituem pelo texto por esta reescrituração infinita da linguagem que se dá como finita pelo acontecimento (e sua temporalidade) em que se enuncia. (GUIMARÃES, 2005, p.28).

Para Guimarães (2007, p.84) a reescrituração é o procedimento pela qual a enunciação diz de outra maneira, em um mesmo texto, aquilo que já foi dito anteriormente, pois dizer novamente não é dizer a mesma coisa, esse procedimento faz com que a reescritura produza um efeito de interpretação diferente ao reescriturado. Desse modo:

A reescrituração é o modo de relação pelo qual a enunciação rediz o que já foi dito. Há reescrituração quando um elemento Y de um texto (uma palavra, uma expressão, por exemplo) retoma um outro elemento $\mathrm{X}$ do texto. Neste caso $\mathrm{Y}$ reescritura $\mathrm{X}$. Este modo de relação enunciativa leva a interpretar uma forma como diferente de si. $\mathrm{O}$ elemento que reescritura atribui (predica) sentido ao reescriturado. Uma característica fundamental da reescrituração é que ela não se caracteriza pelas relações segmentais, ou de contiguidade, própria dos modos de articulação. (GUIMARÃES, 2018, p.85). [grifo em negrito nosso]

Outro procedimento de análises da Semântica do Acontecimento é a relação de articulação que se caracteriza pela relação entre os elementos linguísticos, significando sua contiguidade "uma articulação é uma relação de contiguidade significada pela enunciação" (GUIMARÃES, 2009, p. 51). Não podemos deixar de dizer que:

Nas articulações de dependência e coordenação, o acontecimento especifica uma operação pela qual o Locutor relaciona elementos do enunciado, na articulação por incidência o acontecimento especifica uma operação pela qual o Locutor relaciona a enunciação com o enunciado. (GUIMARÃES, 2009, p.51)

Assim, sempre que existe o funcionamento da operação de predicação, existirão novas determinações, sendo cada predicação novas determinações para a palavra reescriturada, isso mobiliza novos sentidos. A predicação aqui é tomada como "uma operação pela qual, no fio do dizer, uma expressão se reporta a outra, pelos mais variados procedimentos" (GUIMARÃES, 2007, p.84).

E, via tal perspectiva teórica e analítico que buscaremos sustentar a consideração do nosso corpus, em que propomos analisar a relação de sentidos da palavra imigrante presente na Resolução normativa 002/2019. Para tanto, vejamos aqui um outro procedimento descritivo analítico central para as considerações que ensejamos aqui realizar, a cena enunciativa. A configuração da cena enunciativa e as divisões que se dão pelo agenciamento das figuras enunciativas enquanto seres de linguagem, constituem-se em Locutor (L), alocutor-x (al-x) e, Enunciador (E). 


\section{Revista de Estudos Acadêmicos de Letras}

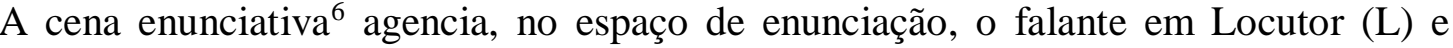
alocutor (al) e se constitui assim a relação de alocução entre L-LT (Locutário), de um lado, e al-at (alocutário), de outro. Nessa relação de alocução vamos considerar as relações de reescrituração e articulação que se apresentam na cena enunciativa. Tal como ele considera, o direito a enunciar é dividido no espaço de enunciação, assim o autor toma a argumentação como política, definida por ele como um modo de sustentar o que se enuncia, a partir de um lugar social de dizer, para seu alocutário.

\section{Análises}

A seguir vamos analisar quatro recortes foi retirado da Resolução normativa 002/2019, publicada no Diário Oficial do Estado de Mato Grosso. O governo do estado de MT secretaria de estado de Gestão - Imprensa oficial. Resolve: "Fixar normas para o acesso à Educação Básica aos imigrantes estrangeiros, residentes fronteiriços, visitantes e apátridas”.

Apresentamos agora as análises dos recortes: em um primeiro momento, observaremos como se dá:

Para falar de "Imigrante" como nome próprio, precisamos considerar alguns aspectos. Primeiro que a palavra "imigrante", no Estatuto do Estrangeiro e na (Lei no 6.815 de 19 de agosto de 1980), é uma palavra que significa no texto do Estatuto uma pessoa que não é nacional (nascida) do Brasil que vieram morar no país era considerada como estrangeira e era vista como uma ameaça à segurança nacional. Está lei servia como uma forma de "proteger" os brasileiros e o próprio território nacional. Em que fica claro em seu 141 artigo da lei, que os deveres dos estrangeiros estavam em maior evidência do que seus direitos. Os estrangeiros que eram mais beneficiados no antigo Estatuto eram os investidores e trabalhadores especializados, como uma empresa Europeia ou Estadunidense que contratava seus nacionais, "expatriados", para trabalhar no Brasil com benefícios legais.

Depois de 37 anos surge a Lei $n^{\circ} 13.445$ de 24 de maio de 2017, chamada de Lei das Migrações. Em que palavra "estrangeiro" é substituída pelas palavras migrante e visitante. Esta nova lei substitui a lei anterior e deixa de ver o imigrante como um intruso ou uma ameaça à segurança nacional. Agora as pessoas não brasileiras têm condições de igualdade aos brasileiros

\footnotetext{
${ }^{6}$ Segundo Guimarães (2002, p. 23), "Uma cena enunciativa se caracteriza por constituir modos específicos de acesso à palavra, dadas as relações entre as figuras da enunciação e as formas linguísticas". Assim, a cena enunciativa é uma configuração e especificação do espaço de enunciação.
} 


\section{Revista de Estudos Acadêmicos de Letras}

ou quase igualdade, tendo acesso à saúde, educação, documentação e ingresso no mercado de trabalho, inclusive da participação de sindicatos. O texto também repudia a xenofobia e o racismo, além de qualquer forma de discriminação como princípio da política migratória.

No Art. $1^{\text {o }}$ da Resolução Normativa 002/2019 que promulgou a convenção sobre Estatuto das Apátridas 13.455/2017, Dispõe sobre os Direitos e os Deveres do Migrante Estrangeiro e do Visitante no Brasil que por decisão da $19^{a}$ Reunião ordinária da Plenária, do dia 24 de setembro de 2019, está resolução vai fixar as diretrizes para a entrada do imigrante estrangeiro na educação básica do estado de Mato Grosso, o que nos chama a atenção é que esta resolução substitui o nome migrante por imigrante.

A Lei de migrante 13.445/2017 regula a entrada e saída do País diferente da Lei 6.815/1980 do Estatuto do Estrangeiro onde regulava só os direitos e garantias dos brasileiros e estrangeiros residentes no País, em contrapartida a lei de migração estabelece os direitos e garantias aos imigrantes e emigrantes, tanto para aquele que imigra como para aquele que emigra. A lei de migração determina imigrante ou emigrante. Passemos agora para as análises dos recortes.

R1 Art.1 ${ }^{\circ}$ Fixar normas para o acesso à Educação Básica, aos imigrantes estrangeiros, residentes fronteiriços, visitantes e apátridas.

Parágrafo único $\mathrm{O}$ público que se refere o caput do artigo, conforme legislação pertinente, assim se define:

a) imigrante: pessoa nacional de outro país ou apátrida que trabalha ou reside e se estabelece, temporária ou definitivamente, no Brasil;

b) residente fronteiriço: pessoa nacional de país limítrofe ou apátrida que conserva a sua residência habitual em município fronteiriço de país vizinho;

c) visitante: pessoa nacional de outro país ou apátrida que vem ao Brasil para estadas de curta duração, sem pretensão de se estabelecer, temporária ou definitivamente, no território nacional;

d) apátrida: pessoa que não é considerada como nacional por nenhum Estado, nos termos da Convenção sobre o Estatuto dos Apátridas, de 1954, assim reconhecida pelo Estado brasileiro, nos termos da legislação em vigor.

(CONSELHO ESTADUAL DE EDUCAÇÃ̃O, 2019, p.31).

A cena enunciativa da Resolução Normativa 002/2019, está constituída em um espaço de enunciação de Língua Portuguesa do Brasil, o Locutor se apresenta como origem daquilo que se enuncia (GUIMARÃES, 2017, p. 32). No agenciamento desta cena o Locutor (L) representa fonte do dizer, porém está afetado pelos lugares sociais que lhe permite dizer, que é o alocutor-CEE/MT (aquele que cria as resoluções) e, que, neste caso, o al-CEE/MT fala pelo enunciador Universal al-x-Estado de MT, para seu (alocutário) at-x imigrantes, e, nestas cenas 


\section{Revista de Estudos Acadêmicos de Letras}

se toma como perspectiva enunciativa, o enunciador universal, "o enunciador-universal é um lugar que significa o Locutor como submetido ao regime do verdadeiro e do falso. Este lugar é próprio do discurso cientifico, embora não seja exclusivo dele" (GUIMARÃES, 2005, p. 26).

Em R1 temos uma articulação por dependência onde a Educação Básica do Mato Grosso é predicada por fixação de normas para aos imigrantes estrangeiros. Podemos observar em R1 que temos um grupo nominal GN “A Educação Básica," incide sobre outro grande grupo nominal "os imigrantes estrangeiros, residentes fronteiriços, visitantes e apátridas" estes são termos que designam imigrantes, em que reescrituram por enumeração/expansão. Ou seja, imigrantes totaliza todos estes termos em seu funcionamento.

Nota-se que foi fixado normas na educação básica do MT para os emigrantes estrangeiros. Fixando assim normas para o acesso à educação básica, produzindo assim uma operação argumentativa através dessa articulação por incidência. O alocutário (sociedade) é apresentado aqui, como "imigrantes estrangeiros, residentes fronteiriços, visitantes e apátridas".

No recorte acima percebemos no espaço de enunciação da língua Portuguesa do Brasil, em que a disputa entre línguas e falantes no qual percebe-se incidência sobre um GN em que incide a obrigatoriedade em outro grupo GN o domínio de Língua portuguesa. E o interessante é que pela paráfrase percebemos que os imigrantes estrangeiros não considerados da mesma forma que os residentes fronteiriços, nem visitantes e nem com apátridas, porem nota-se que existe conforme as definições dos mesmos uma relação sinonímica em que todos os: a) imigrantes, b) residentes fronteiriços, c) visitantes e d) apátridas, são pessoa nacional de outro país, podemos observar a seguinte paráfrase:

$\checkmark$ A educação básica do estado de Mato Grosso, fixa normas para os imigrantes estrangeiros que são considerados pessoas nacional de outro país ou que não é considerada como nacional em nenhum país.

Existe assim uma relação de articulação, e de predicação neste enunciado ao perceber que "fixar normas", estão enumerando os termos "imigrantes estrangeiros, residentes fronteiriços, visitantes e apátridas”, e assim, eles atribuem sentido ao enumerado. Assim Guimarães (2009, p. 60) afirma que "O enumerado atribui sentido aos enumeradores”. Pois “estabelecem princípios e diretrizes", aos enumeradas.

Desse modo temos uma reescrituação por expansão enumerativa. Pois segundo Guimarães (2009), a 


\section{Revista de Estudos Acadêmicos de Letras}

[...] reescrituração, tanto reescrituração por expansão enumerativa quanto enumeração reescrita por totalização. Tal como conceituamos, a reescrituração é uma relação simétrica. Assim se $a$ reescreve $b$ então $b$ reescreve $a$. Desse modo o efeito da expansão enumerativa ou da totalização de uma enumeração aparece como sentidos que se devem ao fato de que na expansão enumerativa a enumeração vem depois e na totalização a enumeração vem antes. Esses sentidos, então, têm a ver com o acontecimento da enunciação e não com uma relação todo/parte estabelecida por antecedência entre os termos que constituem uma enumeração. (GUIMARÃES, 2009, p.67)

Neste presente acontecimento enunciativo, temos uma relação sinonímica de imigrantes estrangeiros onde as definições do caput do Art. $1^{\circ}$ desta resolução determina que os enumerados fixam normas para os imigrantes estrangeiros que são considerados pessoas nacional de outro país ou que não é considerada como nacional em nenhum país.

R2 Art. 20 A Educação Básica, na Política Educacional para os imigrantes estrangeiros, residentes fronteiriços, visitantes e apátridas, será regida pelos seguintes princípios e diretrizes, garantidos no âmbito do Estado de Mato Grosso:

I. igualdade com os nacionais à inviolabilidade do direito à vida, à liberdade, à segurança e à propriedade;

II. acesso a serviços públicos educacionais, sem qualquer discriminação, em razão da nacionalidade e da condição migratória;

III. acesso igualitário e livre a serviços, programas e benefícios sociais, bens públicos, educação, assistência jurídica integral pública, trabalho, moradia, serviço bancário e seguridade social;

IV. proteção integral e atenção ao superior interesse da criança e do adolescente estrangeiro;

V. promoção do reconhecimento acadêmico e do exercício profissional no Brasil, nos termos da lei;

VI. desenvolvimento pleno, seu preparo para o exercício da cidadania e sua qualificação para o trabalho, através da educação, considerada direito de todos, dever do Estado e da família, com a colaboração da sociedade;

VII. igualdade de condições para o acesso e permanência na escola;

VIII. liberdade de aprender, ensinar, pesquisar e divulgar o pensamento, a arte e o saber;

IX. gratuidade do ensino público em estabelecimentos oficiais;

$\mathrm{X}$. direito de ser respeitado por seus educadores;

XI. direito de contestar critérios avaliativos, podendo recorrer às instâncias escolares superiores;

XII. direito de organização e participação em entidades estudantis;

XIII. repúdio e prevenção à xenofobia, ao racismo e a quaisquer formas de discriminação;

XIV. repúdio à discriminação em razão dos critérios ou dos procedimentos pelos quais a pessoa foi admitida em território nacional;

XV. acolhida humanitária;

XVI. igualdade de tratamento e de oportunidade ao migrante e a seus familiares;

XVII. promoção e difusão de direitos, liberdades, garantias e obrigações do migrante;

XVIII. observância ao disposto em tratados. 
(CONSELHO ESTADUAL DE EDUCAÇÃO, 2019, p.32).

Podemos observar em R2 que temos um grupo nominal GN “A Educação Básica, na Política Educacional" incide sobre outro grupo nominal "os imigrantes estrangeiros, residentes fronteiriços, visitantes e apátridas”. Nota-se que foi criado uma Política Educacional na educação básica do MT para os emigrantes estrangeiros. Fixando assim princípios e diretrizes, produzindo assim uma operação argumentativa através dessa articulação por incidência. $\mathrm{O}$ alocutário (sociedade) é apresentado aqui, como "imigrantes estrangeiros, residentes fronteiriços, visitantes e apátridas”. Assim, podemos pensar na seguinte paráfrases.

$\checkmark$ A educação básica do governo do estado de Mato Grosso, desenvolveu uma resolução normativa para estabelecer princípios e diretrizes para os imigrantes estrangeiros, residentes fronteiriços, visitantes e apátridas.

No recorte acima observamos no espaço de enunciação da língua Portuguesa do Brasil, o funcionamento de linguagem presente nesse acontecimento, disputas entre línguas e falantes. E o interessante é que pela paráfrase se observa que os imigrantes estrangeiros são considerados como pessoas nacionais de outro país.

Existe uma relação de articulação, e de predicação neste enunciado ao perceber que “estabelecem princípios e diretrizes", estão enumerando os termos "imigrantes estrangeiros, residentes fronteiriços, visitantes e apátridas”, e assim, atribuem sentido ao enumerado.

\footnotetext{
"Uma articulação é uma relação de contiguidade significada pela enunciação. Em outras palavras, a articulação é um modo de relação enunciativa que dá sentido às contiguidades linguísticas, é, então, uma relação local entre elementos linguísticos que significam pela relação com os lugares de enunciação agenciados pelo acontecimento. (GUIMARÃES, 2018, p.80)
}

Em R2 o GN “A Educação Básica na Política Educacional” articula por dependência de enumeração que é regida pelos “princípios e diretrizes” e que são eles XVIII parágrafos onde vão estabelecendo os princípios e diretrizes desta normativa.

No enunciado R2 percebemos que existe um argumento funcionando com funcionamento do termo "repúdio" nos parágrafos XIII e XIV, ao dizer XIII: "repúdio e prevenção à xenofobia, ao racismo e a quaisquer formas de discriminação; e, repúdio à discriminação em razão dos critérios ou dos procedimentos pelos quais a pessoa foi admitida em território nacional;" é argumento no sentindo de dizer não a xenofobia, ao racismo e a quaisquer formas de discriminação bem como é dizer não a discriminação em razão dos critérios 


\section{Revista de Estudos Acadêmicos de Letras}

pelos quais a pessoa foi admitida em território nacional, lembrando que o "não" presente também como argumento atua no sentido de dizer não a criminalização da migração e não a discriminação, assim o sentido presente neste acontecimento enunciativo insistentemente está querendo dizer sim a equidade e sim a igualdade de direitos e garantias aos imigrantes estrangeiros como em todos os outros parágrafos.

R3 Art. 9 Devem as Mantenedoras do Sistema Estadual de Ensino, sejam municipais e/ ou estadual, selecionar escolas, em cada município, para oferta da Educação Básica ao imigrante estrangeiro, dotando-as das seguintes condições necessárias para este atendimento.

$\S 1^{\circ}$ Os critérios da seleção de escolas são os seguintes:

a) oferta de todas as etapas a Educação Básica;

b) Oferta das modalidades Educação Jovens e Adultos- EJA, Educação Especial e Educação Profissional Técnica de Nível Médio;

c) Realização de levantamento de demanda de migrantes estrangeiros;

$\S 2^{\circ}$ as escolas selecionadas, conforme o caput deste artigo, necessitam atribuir em se quadro:

a) profissional docente graduado em letras, com carga horária especifica, para implementar Língua Portuguesa para estrangeiros;

b) profissional intérprete.

$\$ 3^{\circ}$ cabe ao professor e Língua Portuguesa ministrar suas aulas com metodologias específicas, a fim de permitir ao imigrante estrangeiro o domínio da nossa língua.

$\S 4^{\circ}$ cabe ao profissional intérprete realizar a tradução fiel das aulas ministradas e Língua Portuguesa, até que o estudante tenham domínio da mesma.

$\S 5^{\circ}$ cabe o coordenador pedagógico promover a relação entre a comunidade estrangeira e a comunidade escolar, bem como debater com os professores as metodologias que melhor se adequem à realidade dos estudantes estrangeiros.

$\S 6^{\circ}$ É dever das Mantenedoras do Sistema Estadual, garantir a formação continuada do professor de Língua Portuguesa, do professor integrador e do intérprete. (CONSELHO ESTADUAL DE EDUCAÇÃO, 2019, p.32).

Em R3 enfatiza que as Mantenedoras do sistema Estadual como Municipal tem liberdade de escolher escolas para que seja ofertada Educação Básica para imigrante estrangeiro, a fim de proporcionar ao estudante o domínio da língua portuguesa. Diante do exposto podemos verificar que os processos estão referindo a palavra imigrante estrangeiro de maneira distinta, temos, pois independente das etapas e modalidades implementados, as escolas que ofertam o atendimento aos imigrantes obrigatoriamente devem possuir em seu quadro profissional docente graduado em Letras para implementar Língua Portuguesa para imigrantes bem como, profissional interprete e professor integrador, dispositivos gerais, nas escolas públicas municipais e estaduais que estudam alunos imigrantes, dever-se-á garantir em seu 


\section{Revista de Estudos Acadêmicos de Letras}

quadro de profissionais, o profissional interprete de língua estrangeira. O que se observa neste recorte, é o funcionamento do procedimento de reescrituração pelo qual o termo estudante reescritura imigrante estrangeiro, significando o procedimento como por repetição. $\mathrm{O}$ procedimento de reescrituração por repetição consiste em redizer o que já foi dito, conforme GUIMARÃES, 2018, p.87 “Repetir é redizer”.

Desse modo, nota-se nos incisos terceiro e quarto uma relação de disputa entre línguas e falantes num mesmo espaço de enunciação, pois ao dizer "cabe ao professor de Língua Portuguesa ministrar suas aulas com metodologias específicas, a fim de permitir ao imigrante estrangeiro o domínio a nossa língua" e "cabe ao profissional intérprete realizar a tradução fiel das aula ministradas em Língua Portuguesa, até que o estudante tenham domínio a mesma”. Notamos aqui uma questão de autoridade, onde o estado mostra sua relação de poder para os professores e podemos ter as seguintes paráfrases:

O estado de Mato Grosso diz que cabe ao professor de língua portuguesa ministrar suas aulas até que o estudante tenha o domínio da Língua da Portuguesa.

$\checkmark \quad$ O estado de Mato Grosso diz que cabe ao profissional intérprete realizar a tradução fiel das aulas de Língua Portuguesa até que o estudante tenha o domínio da Língua da Portuguesa.

$\checkmark \quad$ O professor e o intérprete devem ter competência da Língua Portuguesa e transmitir para o estudante/imigrante estrangeiro de maneira eficaz até que o mesmo domine a nossa língua portuguesa.

$\checkmark$ Assim, é possível de se observar quem diz e para quem se diz e desse modo considerar para que direção está o poder do estado e onde se instala o litígio.

Podemos observar a relação que se dá entre a língua no espaço de enunciação, segundo Guimarães (2002, p. 16) “o homem está sempre a assumir a palavra, por mais que esta lhe seja negada", então, dizemos que todo acontecimento se dá num espaço de enunciação, nunca fora dele, e o espaço de enunciação será sempre um espaço recortado pelo funcionamento do político.

Assim, um espaço político constitutivamente está marcado pelas disputas das palavras e das línguas. Entende-se por "político" "conflito entre uma divisão normativa e desigual do real e uma redivisão pela qual os desiguais afirmam seu pertencimento" (GUIMARÃES, 2002, p.16). O político não é, dessa maneira, algo exterior a língua, ao contrário, ele é parte do se funcionamento. A língua é afetada pela exterioridade no espaço de enunciação, no seu 


\section{Revista de Estudos Acadêmicos de Letras}

acontecimento essa distribuição é desigual aos falantes de uma determinada língua. Portanto, nesse enunciado existe essa disputa na relação da língua portuguesa do Brasil, que vem marcada por uma divisão desigual entre línguas e falantes, pela qual os falantes se identificam, pois os estudantes/imigrantes estrangeiros que residem ou residiram em Mato Grosso, devem dominar a língua portuguesa. Uma questão importante a ressaltar, é pensarmos o que o alocutário-estado diz com "domínio da Língua Portuguesa”, fica uma pergunta: será que todos os brasileiros dominam a Língua Portuguesa?

R4 Art. 10 O imigrante estrangeiro deve ser matriculado na escola com objetivo inicialmente, aprender a Língua Portuguesa e, depois, ser incluído no processo de educação formal, através da classificação, tornando-se apto a matricular-se na oferta regular da Educação Básica, conforme prevê a legislação vigente. (CONSELHO ESTADUAL DE EDUCAÇÃO DE MATO GROSSO, 2019, p.32).

Neste R4, do conselho Estadual de Educação do Mato Grosso refere-se ao imigrante estrangeiro, que o estudante deverá ser matriculado na escola que oferta a Política Pública de Educação para imigrantes, com objetivo de aprender a Língua Portuguesa, e ser incorporado no processo de educação formal, e assim que o aluno obtiver as condições necessárias, deverá passar pelo processo de classificação, e, a seguir matricular-se no ensino regular da Educação Básica. Diante desta cena enunciativa a palavra imigrante estrangeiro está sendo reescriturado no processo de sinonímia. E também podemos observar uma reescrituração por substituição do termo domínio em R3 por aprender em R4. Temos a seguinte paráfrase:

$\checkmark$ O estudante/imigrante estrangeiro deve primeiro ter domínio/aprender a língua portuguesa para depois poder ser matriculado no ensino regular da educação básica do Mato Grosso.

No recorte acima podemos observar que ao fazer o procedimento de reescrituração por substituição em que o R3 que diz "domínio" e no recorte 4 "aprender", faz imposição ao imigrante para que tenha competência e o direito de ser matriculado no ensino regular.

\section{Considerações finais}

O presente trabalho teve como objetivo analisar a palavra Imigrante dentro da Resolução Normativa 002/2019 do estado de Mato Grosso, numa perspectiva teórica dos estudos semânticos enunciativos, no qual a atenção foi voltada para o processo de designação, articulação, reescritração e enumeração da palavra nos acontecimentos de linguagem. 


\section{Revista de Estudos Acadêmicos de Letras}

Observamos que é dentro da concepção de política que o conceito de Imigrante é formulado respectivamente, e a configuração do atual paradigma de migração, do sujeito que migra e que querem ser acolhidos pelo país foi o senário para criação desta normativa.

Ao fazer um estudo nestes documentos elencados, perceber-se que não tem nem uma citação detalhada de implantação do ensino da língua espanhola nas escolas do município, não foi identificado qualquer respaldo que beneficie a educação nas duas cidades, por Cáceres ser cidade fronteiriça o projeto cidade gêmeas poderia promover a introdução de ensino de idiomas português/espanhol nas escolas de fronteira Brasil/Bolívia.

Já o sentido de Imigrante nesta normativa articulou-se com o período em que o Brasil está recebendo muitos imigrantes Venezuelanos e Haitianos, e, no estado de Mato Grosso este número cresceu significativamente. Com uma argumentatividade que direciona o sentido da palavra Imigrante, pois é visto como estrangeiro no sentido de forasteiro, aquele que vem de outro país e que supostamente teria seu direito garantido de poder estudar na educação básica do Mato Grosso. Tendo em vista que a educação é um bem primordial e essencial na vida do ser humano, a normativa garante o acesso à educação básica no Mato Grosso, mas articula para o sentido contrário a esse acesso à educação, pois o estudante/imigrante precisa ter o domínio da língua portuguesa para poder ser matriculado numa escola regular. Porém foi observado uma questão de autoridade e imposição em saber, ter domínio da língua portuguesa para poder estudar, mas fica o questionamento o que é ter o domínio de uma língua? Foi feito um levantamento nas escolas do Estado do Mato Grosso e verificou-se que no momento não existe nenhuma escola ofertando este projeto citado na resolução 002/2019 em que o estudante imigrante estrangeiro tem acesso ao ensino aprendizado de Língua Portuguesa na rede pública de ensino básico no estado. Também procuramos e não encontramos nenhuma escola pública que esteja ofertando o ensino de língua portuguesa para imigrante, fica o nosso questionamento. Qual escola está ofertando o ensino de Língua Portuguesa?

Desta forma, podemos olhar para esta normativa que regi o acesso aos estudantes/imigrantes a partir do acontecimento da enunciação. Assim ao estudar a palavra Imigrante tomamos os recortes como precursor das nossas análises.

Tomando este processo de integração do enunciado em que a palavra Imigrante está inserida e podemos citar a transversalidade para dizer que o processo de articulação e reescrituração se instaura uma vez que há uma relação entre o acontecimento de linguagem na Resolução Normativa 002/2019 e que existe um resíduo com a criação da Lei de migração 13.445/2017, mas que na resolução existe uma autenticidade num novo sentido de Imigrante 


\section{Revista de Estudos Acadêmicos de Letras}

que está funcionando neste acontecimento enunciativo, ou seja, a palavra foi usada na lei de migração, em que o sentido de migrante (imigrante/emigrante) está mais globalizado em busca de equidade e igualdade e que neste documento existe uma relação antonímias de Imigrante emigrante, pessoa de outro país que precisa dominar a Língua Portuguesa para ter acesso à educação básica do estado de Mato Grosso.

Portanto na Resolução Normativa 002/2019, o sentido de imigrante, vem acompanhado pela formação nominal de imigrante estrangeiro e que articula para um sentido contrário da Lei de migração, aqui observa-se nesta relação de sinonímia entre imigrante e estrangeiro uma questão de alteridade onde o imigrante estrangeiro precisa dominar a Língua Portuguesa para poder estudar, evidenciando assim a não busca ou implantação de equidade e igualdade para o IMIGRANTE estrangeiro que chega no estado do Mato Grosso.

\section{Referências}

BASE NACIONAL COMUM CURRICULAR - Mec. Disponível em: http://basenacionalcomum.mec.gov.br/images/BNCC_EI_EF_110518_versaofinal_site.pdf. Acesso em 06. dez. 2020.

\section{CONSULTA PÚbLICA PARA A OFERTA DA EDUCAÇÃo BÁSICA PARA.}

Disponível em:

www.mt.gov.br > web > cee > 9806066-consulta-public. Acesso em: 21. Ago.2020.

CONSUlta PÚBLICA PARA A OFERTA dA EDUCAÇÃO BÁSICA. Disponível em: http://www.cee.mt.gov.br/-/9806066-consulta-publica-para-a-oferta-da-educacao-basicapara-imigrantes-estrangeiros. Acesso em: 25. ago. 2020.

Constituição Federal de 1988: O Que É e Onde Encontrar. Disponível em: querobolsa.com.br > revista > constituição-federa. Acesso em: 02. jan. 2021.

Constituição da República Federativa do Brasil de 1988. Disponível em: www.planalto.gov.br. Acesso em 02. jan. 2020

DIAS, L. F. Enunciação e Relações Linguísticas. 1. ed. Campinas: Pontes, 2018. 260p

Diário Oficial da União -DOU - Imprensa Nacional. Disponível em: https://www.in.gov.br/en/web/dou/materia . Acesso em 21.dez. 2020.

GUIMARÃES, Eduardo. Textos e argumentação. Um estudo de conjunções do Português. Pontes. Campinas, 1987.

GUIMARÃES, Eduardo. Semântica do Acontecimento. Campinas-SP:Pontes.2002.

GUIMARÃES, Eduardo. Semântica do acontecimento: um estudo enunciativo da designação. Campinas-SP: Pontes. 2005. 


\section{Revista de Estudos Acadêmicos de Letras}

GUIMARÃES, Eduardo. Semântica do Acontecimento: um estudo enunciativo da designação. 4 ed. Campinas-SP: Pontes. 2017.

GUIMARÃES, Eduardo. Semântica: Enunciação e Sentido. 1. ed. Campinas: Pontes, 2018. v. 1. $280 \mathrm{p}$.

GUIMARÃES, Eduardo. ZOPPI-FONTANA, Mónica; OLIVEIRA, Sheila Elias de. Entrevista com Eduardo Guimarães. Fragmentum (UFSM), v. 40, p. 13-48, 2014a.

KARIM, TAISIR MAHMUDO. Dos nomes à história - o processo constitutivo de um Estado: Mato Grosso. Campinas, SP: [s.n.], 2012.

L13445 - Planalto. Disponível em: http://www.planalto.gov.br/ccivil_03/_ato20152018/2017/lei/113445.htm Acesso em: 20. ago. 2020.

LDB: Lei de Diretrizes e Bases da Educação Nacional. Disponível em: www2.senado.leg.br. Acesso em 01.jan.2021.

Resolução Normativa n ${ }^{\circ}$ 20/2017 -CEE/MT. Disponível em: MINUTA DE RESOLUÇAO NORMATIVA PARA...- CEE/MT. Disponível em: www3.cee.mt.gov.br > aPDownloadArquivo. Acesso em: 21. ago. 2020.

SEDUC. Apesenta Proposta De Política De Educação Para o Imigrante. Disponível Em: file:///D:/Usuario\%2018.08.2020/Downloads/Seduc\%20apresenta\%20proposta\%20de\%20Pol \%C3\%ADtica\%20de\%20Educa\%C3\%A7\%C3\%A3o\%20para\%20o\%20Imigrante\%20\%20Not\%C3\%ADcias\%20-\%20SEDUC.html Acesso em: 20. ago. 2020.

SILVEIRA, D. Apenas 5\% dos municípios com presença de imigrantes e refugiados no Brasil oferecem serviços de apoio. Disponível em: https://g1.globo.com/politica/noticia/2019/09/25/apenas-5percent-dos-municipios-compresenca-de-imigrantes-e-refugiados-no-brasil-oferecem-servicos-de-apoio-aponta-ibge.ghtml Acesso 10. dez. 2020. 